EGU21-13668, updated on 01 Nov 2021

https://doi.org/10.5194/egusphere-egu21-13668

EGU General Assembly 2021

(c) Author(s) 2021. This work is distributed under

the Creative Commons Attribution 4.0 License.

\title{
Soil salinization under different climate change scenarios: A global scale analysis
}

\author{
Nima Shokri ${ }^{1}$, Amirhossein Hassani ${ }^{2}$, and Adisa Azapagic ${ }^{2}$ \\ ${ }^{1}$ Hamburg University of Technology, Institute of Geo-Hydroinformatics, Am Schwarzenberg-Campus 3 (E), 21073 Hamburg, \\ Germany (nima.shokri@tuhh.de) \\ ${ }^{2}$ Department of Chemical Engineering and Analytical Science, The University of Manchester, Sackville Street, Manchester \\ M13 9PL, UK
}

Population growth and climate change is projected to increase the pressure on land and water resources, especially in arid and semi-arid regions. This pressure is expected to affect all driving mechanisms of soil salinization comprising alteration in soil hydrological balance, sea salt intrusion, wet/dry deposition of wind-born saline aerosols - leading to an increase in soil salinity. Soil salinity influences soil stability, bio-diversity, ecosystem functioning and soil water evaporation (1). It can be a long-term threat to agricultural activities and food security. To devise sustainable action plan investments and policy interventions, it is crucial to know when and where saltaffected soils occur. However, current estimates on spatio-temporal variability of salt-affected soils are majorly localized and future projections in response to climate change are rare. Using Machine Learning (ML) algorithms, we related the available measured soil salinity values (represented by electrical conductivity of the saturated paste soil extract, $\mathrm{EC}_{\mathrm{e}}$ ) to some environmental information (or predictors including outputs of Global Circulation Models, soil, crop, topographic, climatic, vegetative, and landscape properties of the sampling locations) to develop a set of data-driven predictive tools to enable the spatio-temporal predictions of soil salinity. The outputs of these tools helped us to estimate the extent and severity of the soil salinity under current and future climatic patterns at different geographical levels and identify the salinization hotspots by the end of the $21^{\text {st }}$ century in response to climate change. Our analysis suggests that a soil area of 11.73 $\mathrm{Mkm}^{2}$ located in non-frigid zones has been salt-affected in at least three-fourths of the $1980-2018$ period (2). At the country level, Brazil, Peru, Sudan, Colombia, and Namibia were estimated to have the highest rates of annual increase in the total area of soils with an $\mathrm{EC}_{\mathrm{e}} \geq 4 \mathrm{dS} \mathrm{m}^{-1}$. Additionally, the results indicate that by the end of the $21^{\text {st }}$ century, drylands of South America, southern and Western Australia, Mexico, southwest United States, and South Africa will be the salinization hotspots (compared to the 1961 - 1990 period). The results of this study could inform decisionmaking and contribute to attaining the United Nation's Sustainable Development Goals for land and water resources management.

1. Shokri-Kuehni, S.M.S., Raaijmakers, B., Kurz, T., Or, D., Helmig, R., Shokri, N. (2020). Water Table Depth and Soil Salinization: From Pore-Scale Processes to Field-Scale Responses. Water Resour. Res., 56, e2019WR026707. https://doi.org/ 10.1029/2019WR026707 
2. Hassani, A., Azapagic, A., Shokri, N. (2020). Predicting Long-term Dynamics of Soil Salinity and Sodicity on a Global Scale, Proc. Nat. Acad. Sci., 117, 52, 33017-33027. https://doi.org/10.1073/pnas.2013771117 